\title{
Direct Lightning Strikes to the Lightning Protective System of a Residential Building: Triggered-Lightning Experiments
}

\author{
Vladimir A. Rakov, Martin A. Uman, Mark I. Fernandez, Carlos T. Mata, Keith J. Rambo, Michael V. Stapleton, \\ and Rafael R. Sutil
}

\begin{abstract}
Lightning triggered from natural thunderclouds using the rocket-and-wire technique was employed in order to subject to direct lightning strikes the lightning protective system of a test house at the International Center for Lightning Research and Testing (ICLRT) at Camp Blanding, FL. The electrical circuit of the test house was connected to the secondary of a padmount distribution transformer located a distance of about $50 \mathrm{~m}$ from the house. The transformer primary was connected to a $650-\mathrm{m}$ long unenergized underground power cable. The test house had two ground rods, one for the lightning protective system grounding and the other for the power supply system grounding. The two rods were about $3 \mathrm{~m}$ apart and were connected by a metallic cable. Lightning current was injected into the lightning protective system ground rod, and the currents and voltages at different points in the test system were measured. The waveshapes of currents in the ground rods of the test house differed markedly from the current waveshapes in other parts of the overall system. The ground rods at the test house appeared to filter out the higher frequency components of the lightning current, allowing the lower frequency components of the current to enter the house's electrical circuit, that is, the ground rods appeared to exhibit a capacitive behavior rather than the often expected resistive behavior. This effect was observed for dc grounding resistances of the rods (driven in sandy soil with conductivity of about $2.5 \times 10^{-4} \mathrm{~S} / \mathrm{m}$ ) ranging from more than a thousand ohms to some tens of ohms. The peak values of 1) the current entering the test house's electrical circuit, 2) the current flowing to the distribution transformer secondary neutral, and 3 ) the current flowing through the surge protective devices at the test house's service entrance were observed to be greater than in either of the two scenarios suggested by the International Electrotechnical Commission.
\end{abstract}

Index Terms-Ground rods, lightning, lightning protective system, surge protective devices.

\section{INTRODUCTION}

W E examine two hypothetical scenarios suggested by the International Electrotechnical Commission (IEC) for the lightning current distribution in the electrical circuit of a residential building equipped with a lightning protective system when this system receives a direct strike. One of these scenarios, suggested by IEC Technical Committee 81 (TC 81) responsible for the lightning protection of structures (J. L. Koepfinger, personal communication, 1998), is illustrated in Fig. 1(a). As seen in this figure, one-half of the total lightning current is assumed to flow in the ground rod of the lightning protective system, one-

Manuscript received November 10, 1999; revised August 31, 2001. The authors are with the Department of Electrical and Computer Engineering, University of Florida, Gainesville, FL 32601 USA.

Publisher Item Identifier S 0885-8977(02)02818-2.

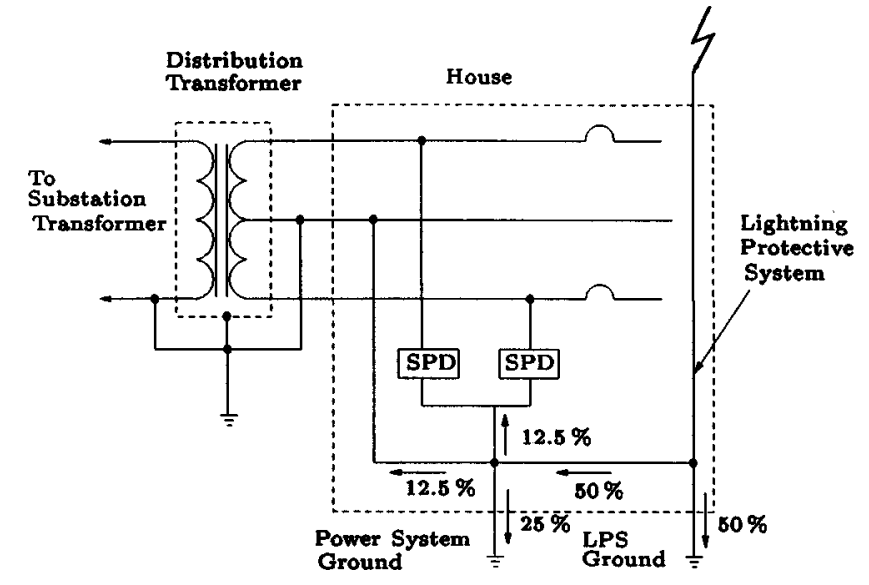

(a)

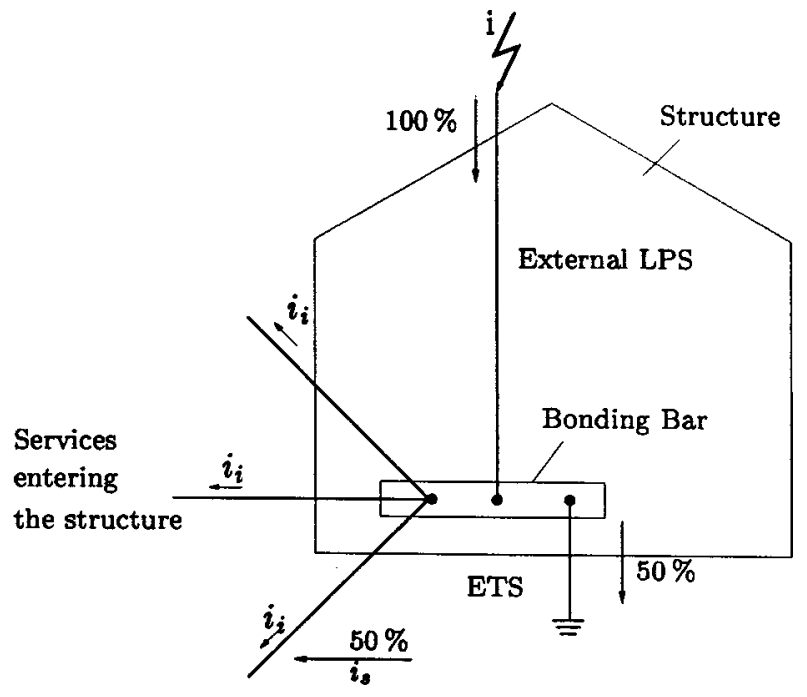

(b)

Fig. 1. (a) Currents in different parts of the electrical circuit of a house when it is struck by lightning, in percent of the injected lightning current, as hypothesized by the International Electrotechnical Commission (J. L. Koepfinger, personal communication, 1998). SPD = surge protective device; LPS = lightning protective system. (b) Division of lightning current between the structure's earth termination (grounding) system, ETS, and services entering the structure, as assumed by IEC 61312-1 (1995) [1]. LPS = lightning protective system.

quarter in the connected power supply system ground rod, and the remaining one-quarter is assumed to enter the electrical circuit of the building. The latter current ( $25 \%$ of the total current) is assumed to split equally between the surge protective devices installed at the service entrance $(12.5 \%$ of the total current) and 


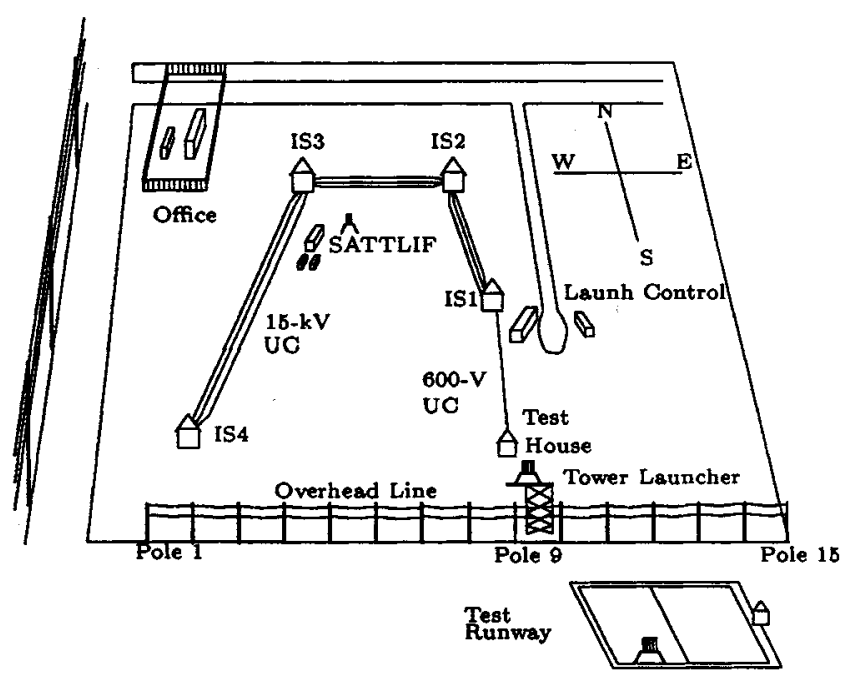

Fig. 2. Overview of the International Center for Lightning Research and Testing (ICLRT) at Camp Blanding, FL, 1997. UC = Underground Cable; IS $=$ Instrument Station

the secondary neutral (12.5\% of the total current). The other scenario is found in the IEC standard IEC 61312-1 [1]. According to this scenario, illustrated in Fig. 1(b), one-half of the total lightning current is assumed to flow to earth via the building's grounding system (including all interconnected ground rods of the building), and the other half is assumed to enter the electrical circuit of the building (in the absence of other metallic services, such as metal gas pipes, entering the building). Thus, in the two IEC scenarios, either $25 \%$ or $50 \%$ of the total lightning current is assumed to enter the building's electrical circuit and flow to the distribution transformer's ground and to other grounds in the system. It is important to note that the IEC current distributions illustrated in Figs. 1(a) and (b) assume that the current waveshapes in all parts of the circuit are the same. We show in this paper that, for triggered lightning striking our test house, a considerably larger fraction of the total lightning current, over $80 \%$, can enter the electrical circuit of the house, and further that the current waveshapes in the ground rods (driven in typical sandy Florida soil) of the test house differ markedly from the current waveshapes in other parts of the test system.

\section{EXPERIMENT}

In 1997, the University of Florida conducted an experiment at the International Center for Lightning Research and Testing (ICLRT) at Camp Blanding, Florida, to study the distribution of lightning current in the electrical circuit of a test house. This electrical circuit was connected via a 50-m underground $600-\mathrm{V}$ triplexed cable to the secondary of a 20-kVA distribution transformer located in instrument station 1 (IS1), as shown in Fig. 2. The $600-\mathrm{V}$ cable was excavated in 2001 , and about 40 pinholes were found in the insulation of its neutral conductor. Thus there is evidence that some current bled off the cable between the test house and IS1 during direct lightning strikes to the test house. The primary of the transformer was connected to a 650-m long underground $15-\mathrm{kV}$, coaxial power cable (one of three shown in Fig. 2), as illustrated in Figs. 3, 7, and 11. The 15-kV cable had an insulating jacket and was run inside a buried PVC conduit. The cable was open-circuited at instrument Station 4 (IS4), and the neutral of the cable was grounded at IS1 and IS4. The test system was unenergized. The test house had two ground rods, one for the lightning protective system grounding (node A) and the other for the power supply system grounding (node B). The two rods were about $3 \mathrm{~m}$ apart and were connected by a braided metallic cable. Since the length of each of the rods was either 3 or $15 \mathrm{~m}$, equal or greater than the separation between them, there was mutual influence between the rods. The measured conductivity of sandy soil at Camp Blanding is about $2.5 \times 10^{-4} \mathrm{~S} / \mathrm{m}$. Lightning was initiated from natural thunderclouds using the rocket-and-wire technique (e.g., Rakov et al. 1998 [2]), and lightning current was injected, via the tower launcher (see Fig. 2) and a 19-m metallic cable, to the ground rod of the test house's lightning protective system (node A). Five flashes, each containing one or more return strokes, were triggered, and their currents were injected into node A, as illustrated in Figs. 3, 7, and 11. Optical observations show no evidence of ground surface arcing from the rods at nodes A and B.

Currents and voltages were recorded with Macrodyne lightning transient recorders (LTRs). LTRs are single-channel recorders with 7-bit amplitude resolution (128 quantization levels) and 5- MHz sampling rate. The LTR stores the digitized input signal into memory only if the input signal changes by more than two quantization levels. This effectively reduces the amplitude resolution by a factor of two, down to 6 bits (64 quantization levels). The effective sampling rate at which data are actually stored into memory is variable depending on the rate of change of the input signal. Portions of the signal with higher rates of change are stored into memory at a rate up to $5 \mathrm{MHz}$, while portions of the signal with lower rates of change are stored into memory at a lower rate. When the input signal is zero or nearly dc, the rate is minimal $76 \mathrm{~Hz}$. LTRs do not have pre-trigger memory nor can they be triggered externally. Trigger thresholds are set individually, and thus, LTRs trigger independently of one another. The alignment of the LTR waveforms is done after the data have been recorded, by examining the entire waveform of each data file and identifying common features in different data records. A more detailed description of the experimental set-up and the salient characteristics of the instrumentation are found in Fernandez et al. [3].

Three different configurations were tested, as specified in Table I and illustrated in Figs. 3, 7, and 11. These configurations were designed to examine the effects of the variation of the resistance of the ground rods at the test house and at IS1 and the presence or absence of MOV surge protective devices (SPDs) at the test house watthour meter. The General Electric watthour meter had two internal 6-kV spark gaps connected between the phase conductor and the neutral. When SPDs (EFI Electronics Corporation Home Guard, mounted at the base of meter) were present, they were connected in parallel with the spark gaps, as seen in Figs. 3 and 7. Although results are presented only for one stroke (identified in Table I) for each configuration, these are representative of the overall data set.

\section{RESULTS}

Currents and voltages at various points of the test system are presented in the following format: for each system configuration, an electrical diagram is given (see Figs. 3, 7, and 11) on which current measurement points are indicated by a circle la- 


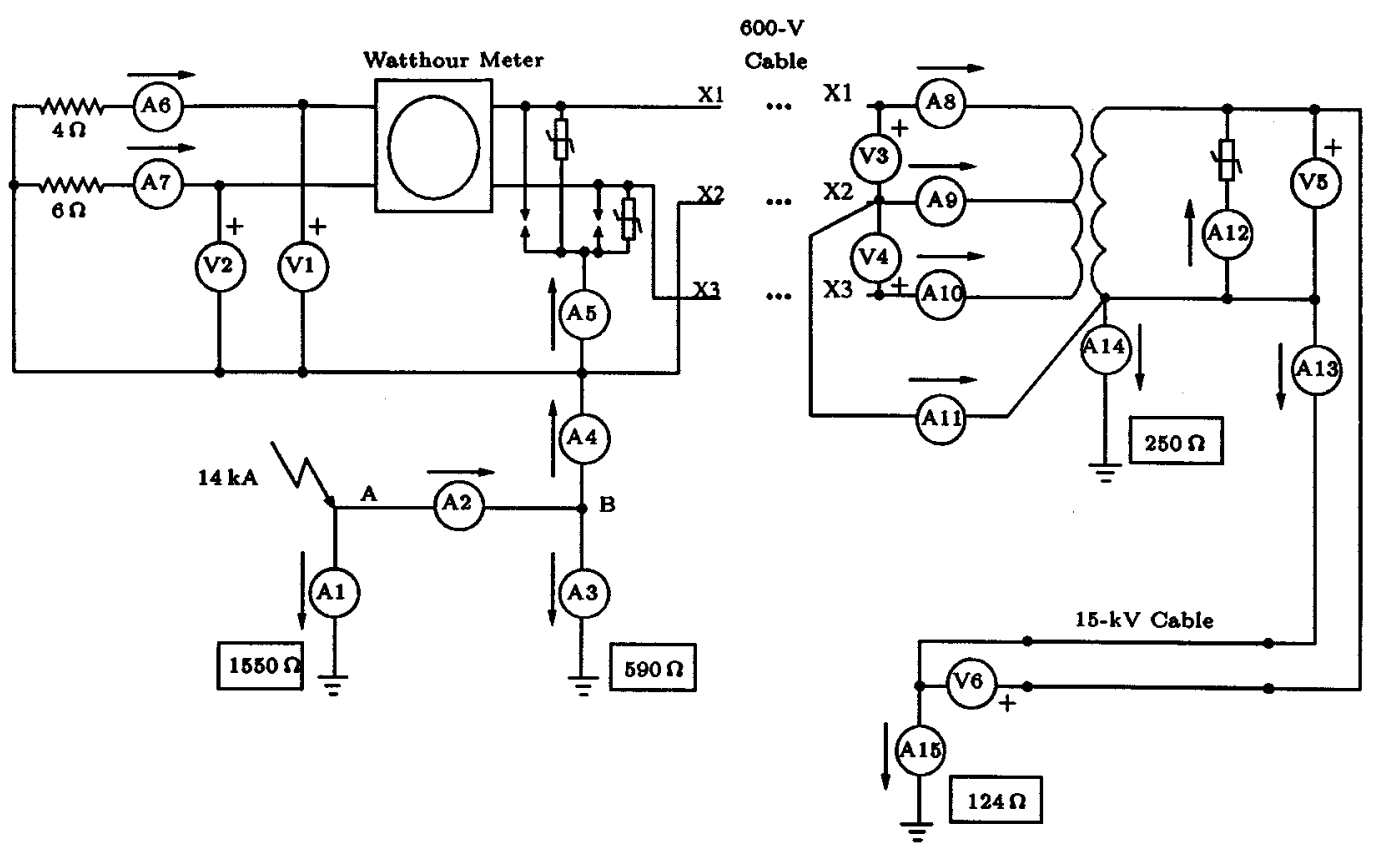

Fig. 3. Electrical diagram of test configuration 97-A (see Table I).

TABLE I

DESCRIPTIONS OF THE TESTED SYSTEM CONFIGURATIONS

\begin{tabular}{|c|c|c|}
\hline Description of the System Configuration & $\begin{array}{c}\text { Configuration } \\
\text { Identifying Symbol }\end{array}$ & $\begin{array}{l}\text { Test Lightning Event } \\
\text { and Stroke Number }\end{array}$ \\
\hline $\begin{array}{l}\text { - Relatively high grounding resistances at the test } \\
\text { house: } 1550 \Omega \text { (ground } \mathrm{A}, 3 \mathrm{~m} \text { ), and } 590 \Omega \text { (ground } \\
\mathrm{B}, 3 \mathrm{~m}) \text {. } \\
\text { - Surge protective devices installed. } \\
\text { - Relatively high grounding resistance at IS1 } \\
(250 \Omega, 6 \mathrm{~m}) \text {. } \\
\text { - Grounding resistance at IS4: } 124 \Omega(6 \mathrm{~m}) \text {. }\end{array}$ & $97-\mathrm{A}$ & Flash 9706, Stroke 2 \\
\hline $\begin{array}{l}\text { - Relatively low grounding resistances at the test } \\
\text { house: } 41 \Omega \text { (ground A, } 15 \mathrm{~m} \text { ), and } 76 \Omega \text { (ground B, } \\
15 \mathrm{~m} \text { ). } \\
\text { - Surge protective devices installed. } \\
\text { - Relatively low grounding resistance at IS1 }(69 \Omega \text {, } \\
12 \mathrm{~m} \text { ). } \\
\text { - Grounding resistance at IS4: } 124 \Omega(6 \mathrm{~m}) \text {. }\end{array}$ & 97-B & Flash 9736, Stroke 2 \\
\hline $\begin{array}{l}\text { - Relatively low grounding resistances at the test } \\
\text { house: } 41 \Omega \text { (ground A, } 15 \mathrm{~m} \text { ), and } 76 \Omega \text { (ground } \mathrm{B} \text {, } \\
15 \mathrm{~m} \text { ). } \\
\text { - Surge protective devices not installed. } \\
\text { - Relatively low grounding resistance at IS1 }(69 \Omega \text {, } \\
12 \mathrm{~m} \text { ). } \\
\text { - Grounding resistance at IS4: } 124 \Omega(6 \mathrm{~m}) \text {. }\end{array}$ & $97-\mathrm{C}$ & Flash 9717, Stroke 3 \\
\hline
\end{tabular}

beled with an A followed by a number, and voltage measurement points are indicated by a circle labeled with a $\mathrm{V}$ followed by a number. Measured low-frequency, low-current values of ground impedance, which we refer to as dc resistances, and the peak value of injected lightning current are specified. The injected lightning current was determined by the summation of the measured current flowing in the ground rod at node $\mathrm{A}$ and the measured current flowing from node A to node B. The total 
lightning current peak measured at the tower launcher, mounted on top of an 11-m high wooden tower, was somewhat larger than the injected current peak, presumably due to flashovers to ground from the metallic cable connecting the rocket launcher to node A. Arrows in Figs. 3, 7, and 11 indicate the direction of negative charge flow. In this paper, we focus on testing the validity of the IEC-suggested divisions of lightning current, as illustrated in Figs. 1(a) and (b). However, for configurations 97-A and 97-B, we present for completeness all current and voltage measurements obtained. No data are available for the current in the ground rod at IS4 (A15), but it is probably not much different from the current entering the cable neutral at IS1 (A13), since the cable had a polyethylene jacket and was inside PVC conduit. Each current waveform (see Figs. 4, 5, 8, 9, and 12) is labeled with the measurement location identification symbol given in the electrical diagram (see Figs. 3, 7, and 11). The current waveforms are grouped in two sets. The first set includes the injected lightning current and currents A1, A3, and A4 (A1 and A3 for configuration 97-B). The second set includes current A4 and all other measured currents. Note that the positions of some measurement points for configuration 97-B differ from those for configurations 97-A and 97-C. Measured voltage waveforms for configurations 97-A and 97-B are shown in Figs. 6 and 10, respectively. Both current and voltage waveforms are displayed on a $200 \mu$ s time scale.

\section{A. Configuration 97-A}

In this test configuration, shown in Fig. 3, the ground rod at the test house that simulated the lightning protective system grounding (node A in Fig. 3) and the ground rod that simulated the power supply system grounding (node B in Fig. 3) each had a length of about $3 \mathrm{~m}$. Ground rods at IS1 and IS4 each had a length of about $6 \mathrm{~m}$. The dc resistances, which are relatively high, of the two ground rods at the test house, as well as the resistances of the ground rods at IS1 and IS4, are given in Table I and in Fig. 3. The dc resistance of the ground rod at node A $(1550 \Omega)$ was almost a factor of three higher than that at node $\mathrm{B}(590 \Omega)$, possibly due to inhomogeneity of soil in the vicinity of the test house. Note that IEC 61 024-1 [4] contains no requirement for the value of grounding resistance of an ordinary building for which protection level III/IV is selected. Such buildings are only required to have at least two ground electrodes, either vertical of $2.5 \mathrm{~m}$ length or horizontal of $5 \mathrm{~m}$ length, regardless of soil conductivity. Injected lightning current, currents to ground at the test house, and current into the house's electrical circuit are shown in Fig. 4.

The total lightning current measured at the tower launcher had a negative peak of about $17 \mathrm{kA}$, a $10-90 \%$ risetime of about $1 \mu \mathrm{s}$, and a half-peak width of $60 \mu \mathrm{s}$. The injected lightning current, shown in Fig. 4(a), had a negative peak of about $14 \mathrm{kA}$. The current to ground at the first ground rod (node A in Fig. 3) in Fig. 4(b) has a negative peak of about $2.8 \mathrm{kA}$, with a 10-90\% risetime and a half-peak width of 0.4 and $0.9 \mu$ s, respectively. The current to ground at the second ground rod (node B in Fig. 3) in Fig. 4(c) has a negative peak of about $1.8 \mathrm{kA}$ and a waveshape which is similar to that of the current in the first ground rod. The current that flowed into the electrical circuit of the test house,

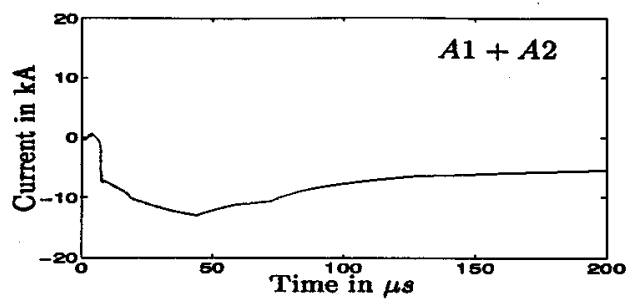

(a)

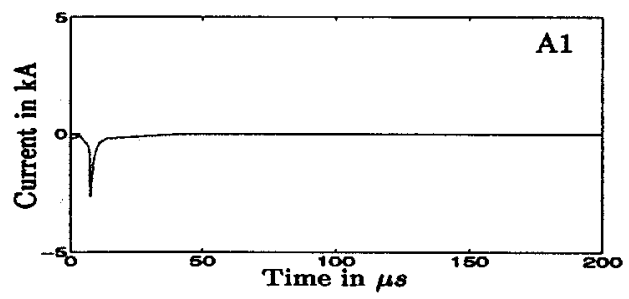

(b)

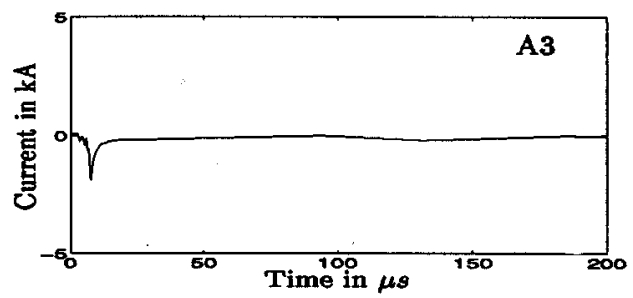

(c)

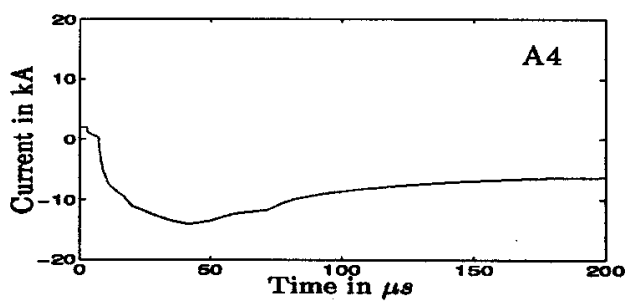

(d)

Fig. 4. Current versus time waveforms for configuration 97-A (see Table I). (a) Injected lightning current $[\mathrm{A} 1+\mathrm{A} 2]$. (b) Current to ground at node A $(1550 \Omega)$ [A1]. (c) Current to ground at node B $(590 \Omega)$ [A3]. (d) Current entering the test house's electrical circuit [A4].

shown in Fig. 4(d), has a negative peak value of about $14 \mathrm{kA}$. This current waveform apparently represents an injected lightning current which has been "filtered" by the two ground rods. The ground rods apparently removed primarily the higher frequency components of the lightning current, allowing the lower frequency components to flow into the house's electrical circuit. Interestingly, the peak value of current in the higher-resistance rod at node $\mathrm{A}$ is appreciably higher than that in the lower-resistance rod at node B. The amplitude of the "filtered" current waveform [Fig. 4(d)] is essentially the same as the amplitude of the injected lightning current waveform. Thus the ground rods appear to act as shunt capacitors that appreciably degrade the front of the current waveform entering the service entrance [compare waveforms in Fig. 4(a) and (d)] but do not much influence the peak current value, the current peak remaining essentially the same (within the measurement error of 15 to $20 \%$ ) in this particular case. Note that in studies of the transient behavior of grounding systems the capacitance of grounding electrodes in 


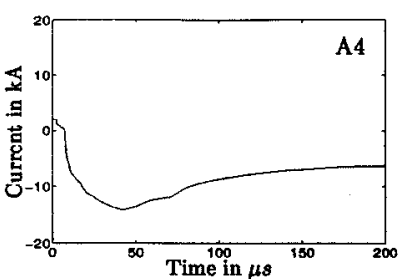

(a)

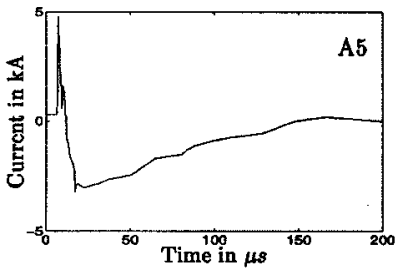

(b)

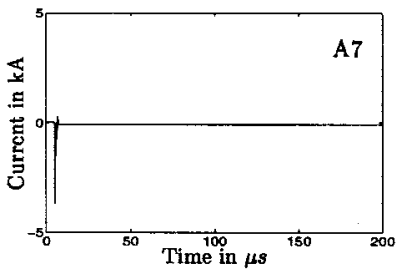

(c)

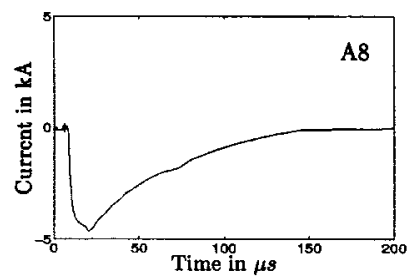

(d)

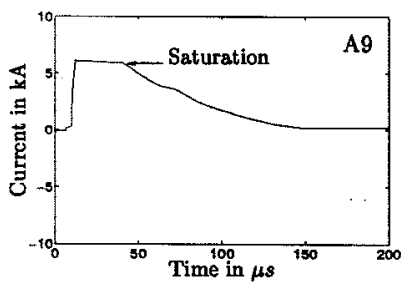

(e)

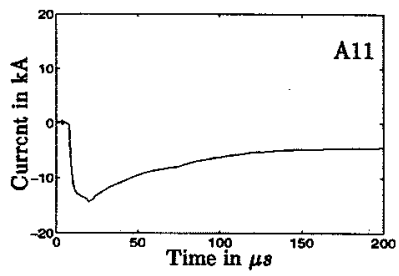

(f)

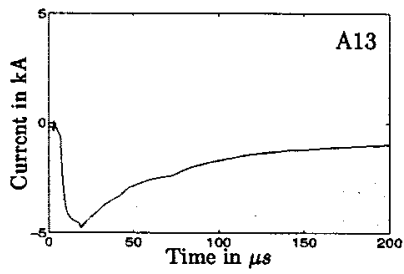

(g)

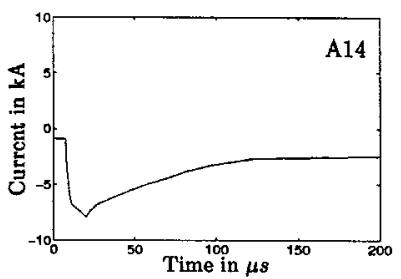

(h)
Fig. 5. Current versus time waveforms for configuration 97-A (see Table I) (a) Current entering the test house's electrical circuit [A4]. (b) Currents through SPD's [A5]. (c) Current through 6- $\Omega$ load resistor [A7]. (d) Phase current X1 in transformer secondary [A8]. (e) Transformer secondary neutral current X2 [A9]. (f) Current from secondary neutral X2 to primary neutral [A11]. (g) Primary neutral current to cable [A13]. (h) Current to ground at IS1 (250 $\Omega$ ) [A14].

high-conductivity soils, which is not the case at Camp Blanding, is usually neglected (e.g., Rakotomalala et al., 1994 [5]).

The current injected into the service entrance [Fig. 5(a)] splits between the SPDs, the load resistors, and the service entrance neutral X2. The SPD current in Fig. 5(b) exhibits a bipolar waveform with a positive peak of about $4.7 \mathrm{kA}$ followed by a negative peak of about $3.2 \mathrm{kA}$. The current through the $6-\Omega$ load resistor in Fig. 5(c) has a negative maximum peak of about $3.6 \mathrm{kA}$, some oscillations [unresolved in Fig. 5(c)], and a very short overall duration of about $2 \mu \mathrm{s}$. This short current pulse corresponds to the narrow positive spike in the SPD current [Fig. 5(b)]. The phase current X1 in the transformer secondary, shown in Fig. 5(d), has a negative peak of about $4.7 \mathrm{kA}$ and appears to decay to zero at about $140 \mu \mathrm{s}$. The phase currents in the transformer secondary converged in the transformer secondary neutral. The neutral current X2 in the transformer secondary, shown in Fig. 5(e), exceeded the upper measurement limit of $6.1 \mathrm{kA}$. The waveform re-

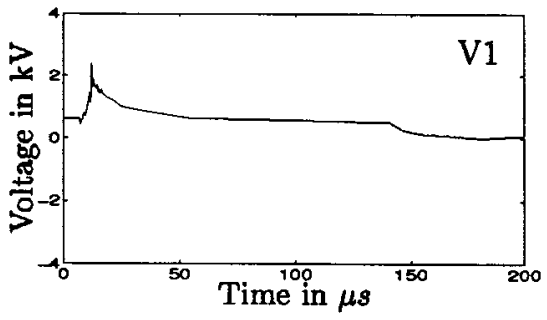

(a)

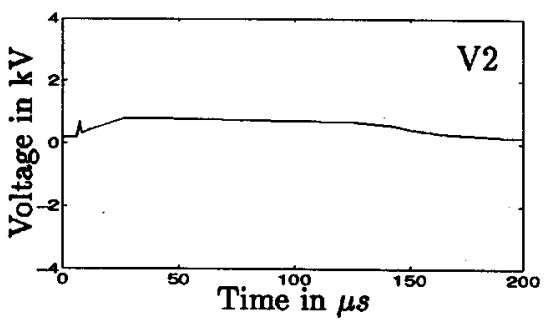

(b)

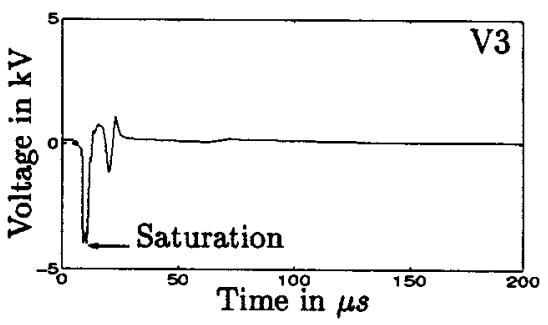

(c)

Fig. 6. Voltage versus time waveforms for configuration 97-A (see Table I). (a) Voltage between phase X1 and neutral X2 in the test house [V1]. (b) Voltage between phase X3 and neutral X2 in the test house [V2]. (c) Voltage between phase $\mathrm{X} 1$ and neutral $\mathrm{X} 2$ at the transformer secondary [V3].

mained saturated for $30 \mu$ s and decayed in the same manner as the phase current X1 in the transformer secondary [Fig. 5(d)]. The current from the secondary neutral of the transformer to the primary neutral in Fig. 5(f) has a negative peak of about $14 \mathrm{kA}$, and it is similar in shape to the phase current X1 in the transformer secondary [Fig. 5(d)]. The primary neutral current to the $15-\mathrm{kV}$ underground cable in Fig. 5(g) (probably similar to current flowing to ground at IS4) has a negative peak of about $4.8 \mathrm{kA}$. This current is also similar in shape to the phase current $\mathrm{X} 1$ in the transformer secondary [Fig. 5(d)]. The current to ground at IS1 in [Fig. 5(h)] has a negative peak of about $7.9 \mathrm{kA}$. At $50 \mu \mathrm{s}$, the ratio of currents to ground at IS1 [Fig. 5(h)] and into the $15-\mathrm{kV}$ cable neutral [Fig. $5(\mathrm{~g})]$ is approximately $2: 1$.

All measured voltage waveforms are shown in Fig. 6. The voltage between phase $\mathrm{X} 1$ and neutral $\mathrm{X} 2$ in Fig. 6(a) has a positive peak of about $2.4 \mathrm{kV}$. Then it remains at about $550 \mathrm{~V}$ for $130 \mu \mathrm{s}$ and finally decays to nearly zero. The voltage between phase X3 and neutral X2 in Fig. 6(b) has a positive spike of about $700 \mathrm{~V}$ and exhibits a plateau at about $750 \mathrm{~V}$ lasting for $100 \mu \mathrm{s}$ or so. It appears that the SPDs at the test house watthour meter operated. The voltage between phase X1 and neutral X2 at the transformer secondary, shown in Fig. 6(c), appears as a sequence of two bipolar pulses the first of which has a negative peak of about $4 \mathrm{kV}$ (likely clipped). The time separation between the negative peaks of the two pulses is about $11 \mu \mathrm{s}$. 


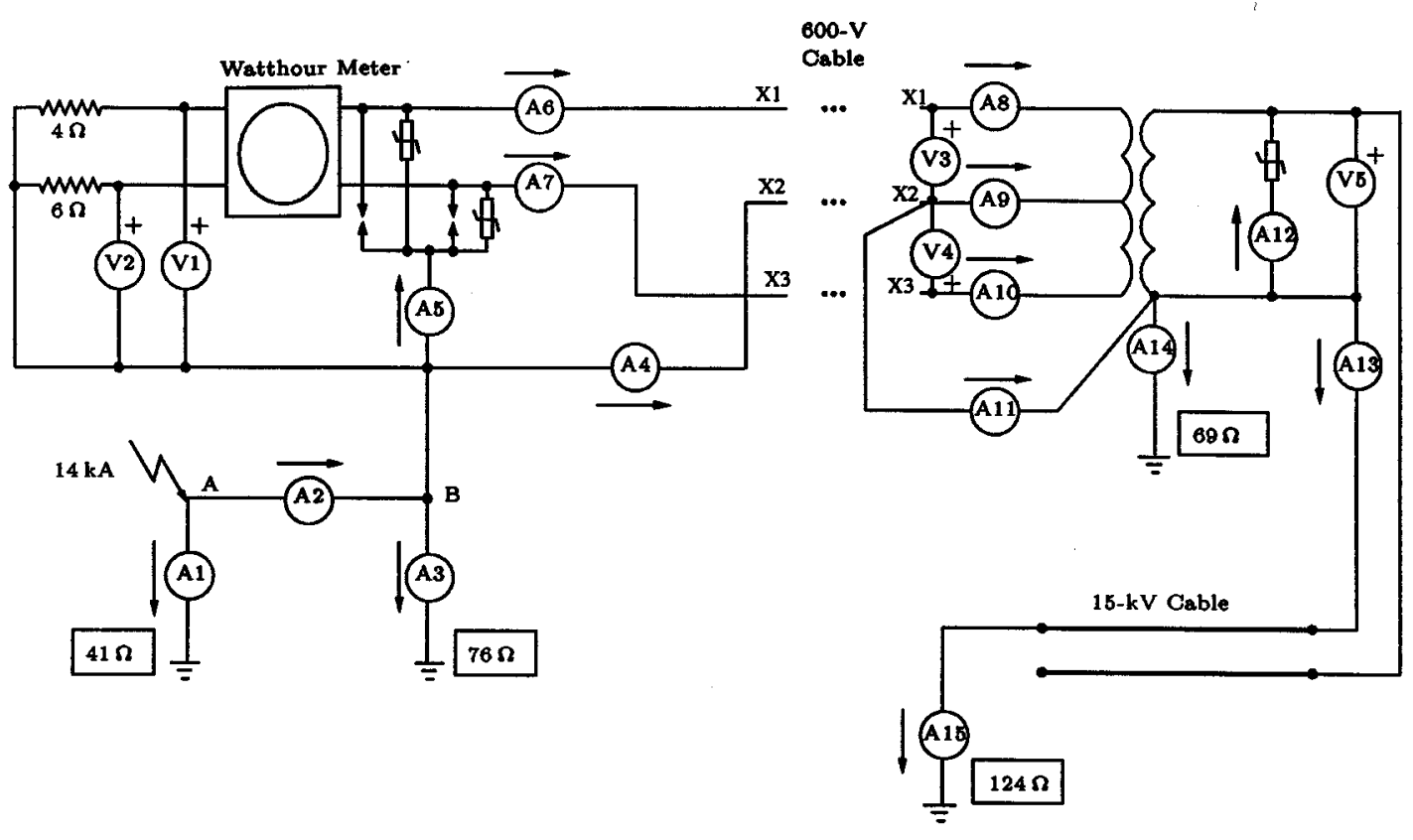

Fig. 7. Electrical diagram of test-system configuration 97-B (see Table I).

The major result from this test is the observation that the current waveshapes in the ground rods at the test house differ markedly from the current waveshapes in other parts of the system. The rods had a length of about $3 \mathrm{~m}$ and were driven in typical sandy Florida soil whose measured conductivity was about $2.5 \times 10^{-4} \mathrm{~S} / \mathrm{m}$. The bulk of the lightning current appears to have been forced into the distribution system earthing (ground rods at IS1 and IS4), with the ground rods at the test house taking the primarily higher frequency components associated with the initial rising portion of the injected lightning current.

\section{B. Configuration 97-B}

The major difference between test configuration 97-B and configuration $97-\mathrm{A}$ is the lowered ground rod resistances at the test house, at node A from $1550 \Omega$ in 97 -A to $41 \Omega$, at node B from $590 \Omega$ in $97-A$ to $76 \Omega$, and at the transformer in IS1 from $250 \Omega$ in $97-A$ to $69 \Omega$. The dc resistance of the ground rod at IS4 remained the same, $124 \Omega$. The lowering of the resistances of the ground rods was accomplished by increasing the length of each of these rods. The lengths of the two rods at the test house were increased from 3 to about $15 \mathrm{~m}$ and the length of the rod at IS1 from 6 to about $12 \mathrm{~m}$. The test-system configuration 97-B is shown in Fig. 7. Note that there are a few changes with respect to configuration 97-A shown in Fig. 3. In particular, the total current entering the test house was not measured in configuration 97-B, but it can be estimated by subtracting current A3 from current A2. Also, instead of measuring currents through the load resistors, currents flowing along X1 and X3 toward the transformer (A6 and A7) were measured.

Injected lightning current and currents to ground at the test house are shown in Fig. 8. The total lightning current measured at the tower launcher had a negative peak of about $19 \mathrm{kA}$, a $10-90 \%$ risetime of $0.6 \mu \mathrm{s}$, and a half-peak width of $57 \mu \mathrm{s}$. The injected lightning current shown in Fig. 8(a) had a negative peak of about $14 \mathrm{kA}$. Similar to configuration 97-A, currents

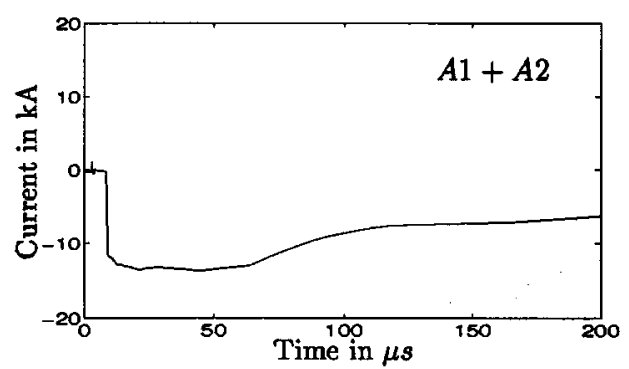

(a)

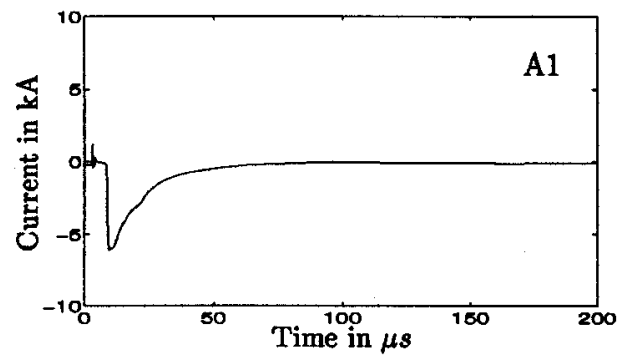

(b)

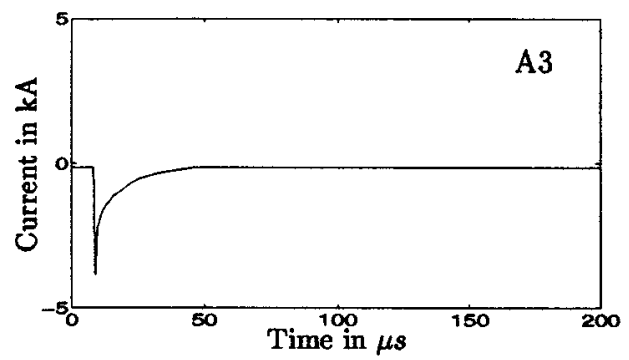

(c)

Fig. 8. Current versus time waveforms for configuration 97-B (see Table I). (a) Injected lightning current [A1+A2]. (b) Current to ground at node A (41 $\Omega$ ) [A1]. (c) Current to ground at node B $(76 \Omega)$ [A3].

to ground A1 and A3 exhibit appreciably narrower waveshapes than does the injected lightning current. Note that, as opposed 




(a)

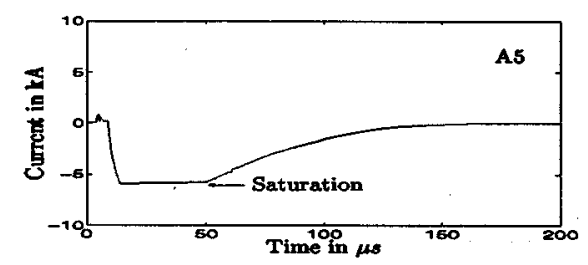

(b)

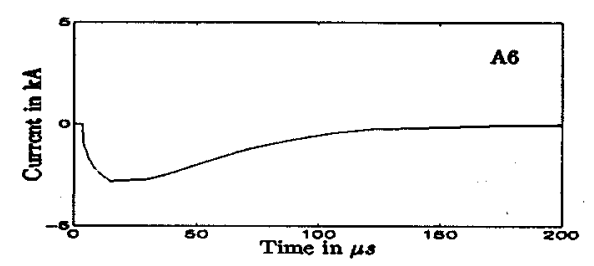

(c)

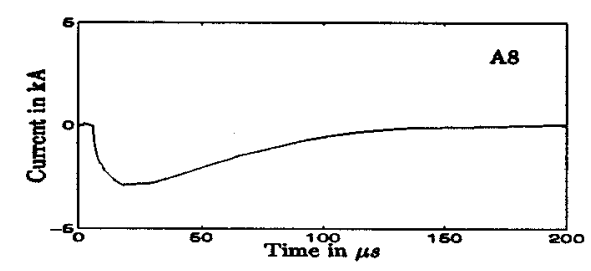

(d)

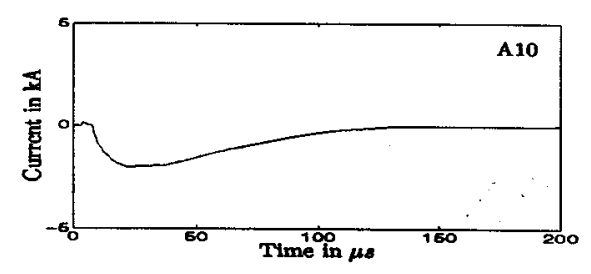

(f)

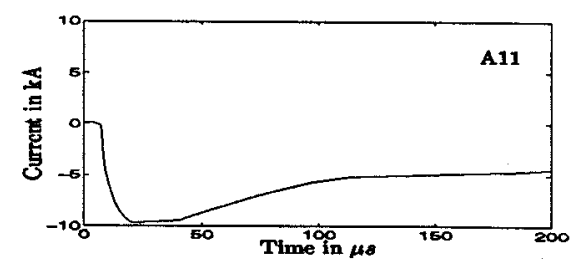

(g)

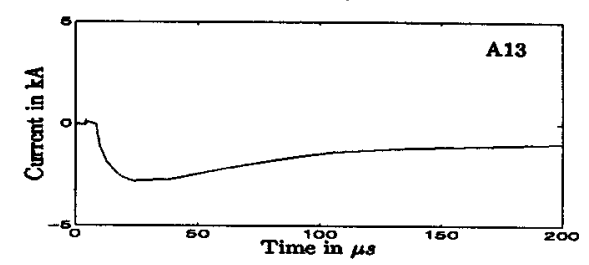

(h)

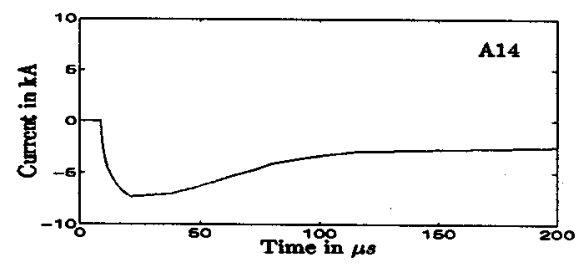

(i)

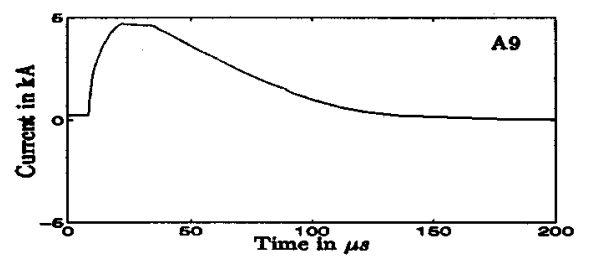

(e)

Fig. 9. Current versus time waveforms for configuration 97-B (see Table I). (a) Test house neutral current to the transformer [A4]. (b) Currents through SPDs [A5]. (c) Test house phase current X1 [A6]. (d) Transformer secondary phase current X1 [A8]. (e) Transformer secondary neutral current X2 [A9]. (f) Transformer secondary phase current X3 [A10]. (g) Current from secondary neutral X2 to primary neutral [A11]. (h) Primary neutral current to cable [A13]. (i) Current to ground at IS1 $(69 \Omega)$ [A14].

to configuration $97-\mathrm{A}$, the peak current in the higher-resistance rod at node B is lower than in the lower-resistance rod at node $\mathrm{A}$. The peak current entering the house's electrical circuit is about $93 \%$ (versus essentially $100 \%$ for configuration $97-\mathrm{A}$ ) of the injected lightning current peak. All other measured currents are shown in Fig. 9, and all measured voltages in Fig. 10. Similar to configuration $97-\mathrm{A}$, at $50 \mu \mathrm{s}$ the ratio of the currents to ground at IS1 and into the cable neutral is approximately 2:1.

\section{Configuration 97-C}

Configuration 97-C is identical to configuration 97-B except for the absence of SPD's at the watthour meter. Configuration
97-C was field tested before configuration 97-B but is presented last because we chose to illustrate first the influence of $\mathrm{dc}$ grounding resistance while SPDs were installed at the meter. The test-system configuration $97-\mathrm{C}$ is shown in Fig. 11. Although the SPDs were absent, the built-in protective spark gaps were present and apparently operated providing a path for the current to flow through the phase conductors to the transformer secondary. Further, there is video evidence that there were sparks in and around the service panel during this test, and the meter incurred considerable physical damage. Injected lightning current, currents to ground at the test house, and current into the house's electrical circuit are shown in Fig. 12. The total 


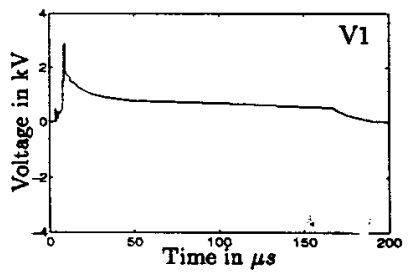

(a)

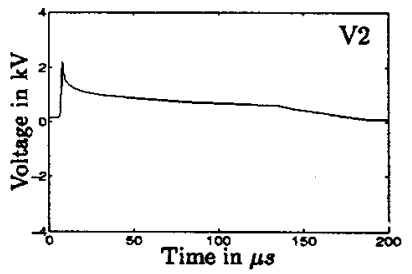

(b)

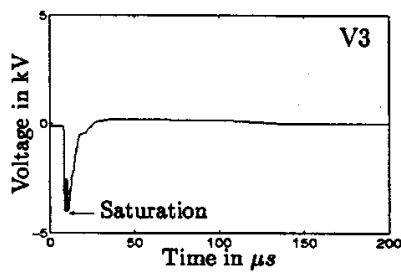

(c)

Fig. 10. Voltage versus time waveforms for configuration 97-B (see Table I). (a) Voltage between phase X1 and neutral X2 in the test house [V1]. (b) Voltage between phase X3 and neutral X2 in the test house [V2]. (c) Voltage between phase $\mathrm{X} 1$ and neutral $\mathrm{X} 2$ at the transformer secondary [V3]

lightning current measured at the tower launcher had a negative peak of about $12 \mathrm{kA}$, a $10-90 \%$ risetime of about $0.46 \mu \mathrm{s}$, and a half-peak width of about $32 \mu \mathrm{s}$. The injected lightning current shown in Fig. 12(a) had a negative peak of about $9.8 \mathrm{kA}$. Similar to the previous two configurations, the ground rods appeared to filter out the higher frequency components of the lightning current, allowing the lower frequency components to enter the house's electrical circuit. The amplitude of the "filtered" current waveform [Fig. 12(d)] is about $81 \%$ of the amplitude of the injected lightning current waveform. At $50 \mu \mathrm{s}$, the ratio of currents flowing to ground at IS1 and into the cable neutral is approximately 3:1 versus $2: 1$ for configurations $97-\mathrm{A}$ and 97-B.

\section{Discussion}

A summary of selected peak currents, measured at the test house for the three different configurations (see Table I), is given in Table II. Note that the SPDs were absent in configuration 97-C, and that the built-in spark gaps apparently operated. Also included in Table II is the IEC-suggested current distribution illustrated in Fig. 1(a) as well as the current assumed to flow into the house's electrical circuit in the IEC-suggested current distribution presented in Fig. 1(b). For the IEC distributions, the peak value of the injected lightning current is assumed to be $100 \mathrm{kA}$ [4], which corresponds to a severe lightning discharge. It is important to note that the IEC distribution implies the same current waveshape in the different paths, so that current peaks add to $100 \%$, whereas our measurements indicate that the currents in the ground rods at the test house significantly differ in shape from the currents in other parts of the circuit. As a result of that and for other reasons, the measured current peaks in Table II do not add to $100 \%$. As seen from Table II, the peak value of the current into the test house is from 81 to $100 \%$ of the injected current peak, whereas the IEC hypothesized either $25 \%$ [Fig. 1(a)] or $50 \%$ [Fig. 1(b)].

The two IEC scenarios illustrated in Figs. 1(a) and (b) are for the case when "individual evaluation is not possible" [1]. Such individual evaluation is sometimes done assuming that the current division is determined by the low-frequency, low-current ground resistances of the system (the injected current divides as the inverse dc grounding resistances in the system). This approach, although clearly invalid for the initial, fast-rising portion of the lightning current, is consistent with the IEC assumption that the currents in different parts of the system have the same waveshapes. We now consider the distribution of current as a function of the dc grounding resistances in the system, computed using the IEC approach by A. Rousseau, and show that this distribution is inconsistent with the experimental data. We will discuss the influence of inductance in the next paragraph. There were four ground rods in the system, two at the test house and one at each IS1 and IS4. Table III gives distributions of peak currents (in percent of the injected current peak), for each test-system configuration, computed by A. Rousseau, together with measured peak current distributions. Recall that the distance between the two rods at the test house is $3 \mathrm{~m}$, between the test house and IS1 $50 \mathrm{~m}$, and between IS1 and IS4 $650 \mathrm{~m}$.

As seen in Table III for configuration 97-A, there is an agreement between the computed and measured percentages of peak current into the test house and into the ground rod at node B, while the measured and computed percentages of peak current into the ground rod at node A differ by a factor of 5. Furthermore, the division of current between the two rods at the test house predicted by the ratio of their dc grounding resistances is reverse with respect to the observed division. For configurations 97-B and 97-C, the computed and measured divisions of current between the two ground rods at the test house are similar (particularly for configuration 97-B), but the computed percentage of current into the house is considerably (by a factor of 2 to 3 ) lower than observed. Thus the dc grounding resistances do not control the distribution of peak currents in the test system, as also evidenced by the very different waveshapes of currents measured in different parts of the circuit. Specifically, the currents that flowed in the two ground rods at the test house appeared as relatively narrow pulses (particularly for configuration 97-A), suggesting that predominantly higher-frequency components of the injected lightning current entered these two ground rods. As further discussed below, this indicates a capacitive behavior of the rods. Bejleri et al. [6], who studied lightning strikes to a buried counterpoise connected to three $2.4-\mathrm{m}$ vertical ground rods, reported that currents in the vertical rods exhibited considerably narrower waveforms than the injected lightning currents. The observation of very different current waveshapes in different part of the system indicates that current peaks are not suitable for the examination of current sharing. We suggest that charge transfer might be a better quantity for such an analysis, since 


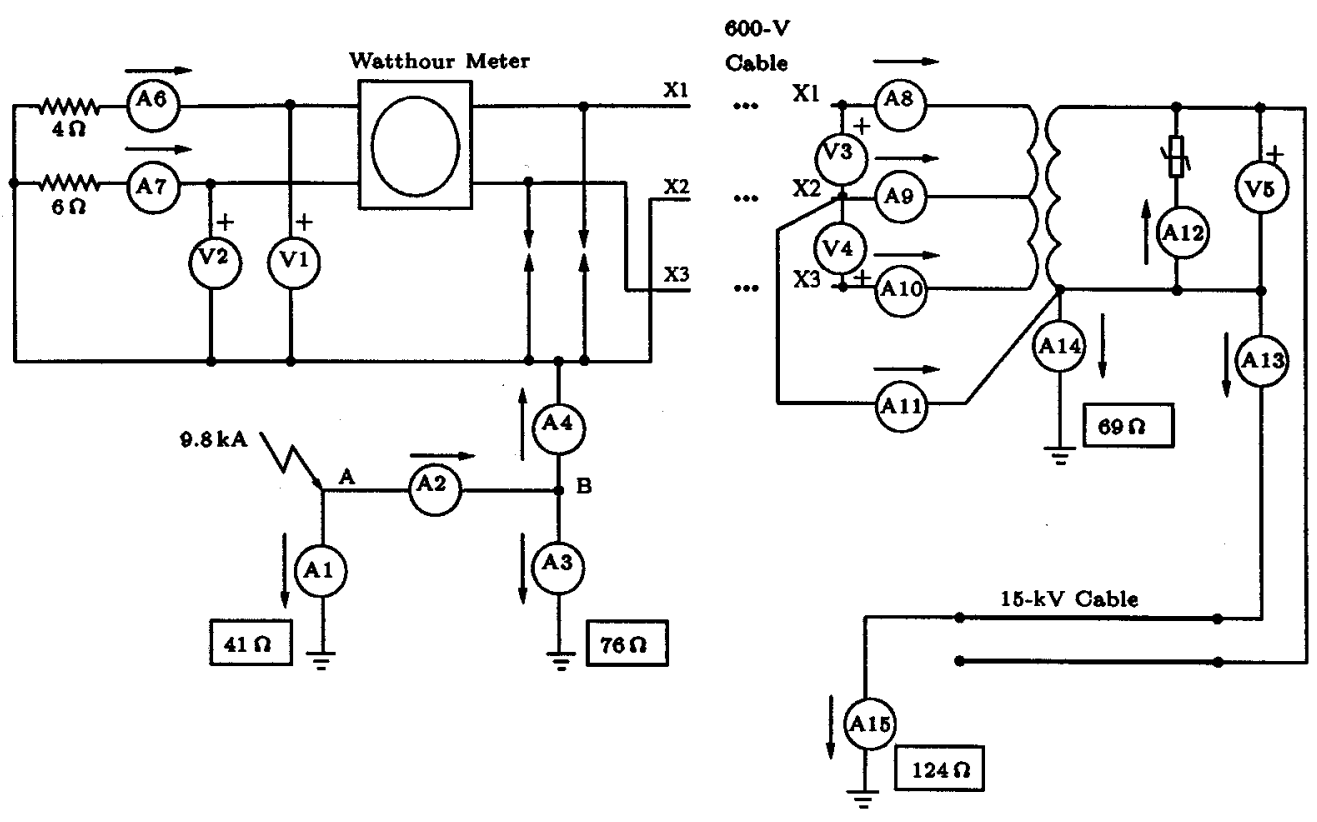

Fig. 11. Electrical diagram of test-system configuration 97-C (see Table I).

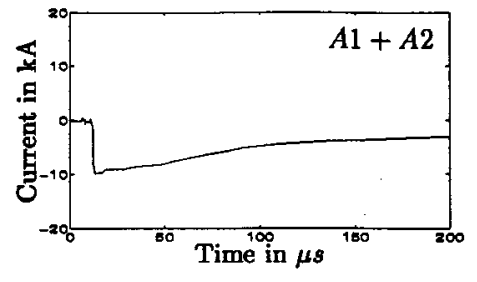

(a)

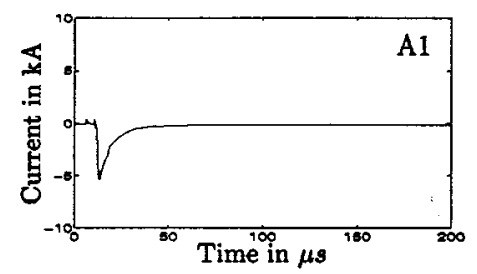

(b)

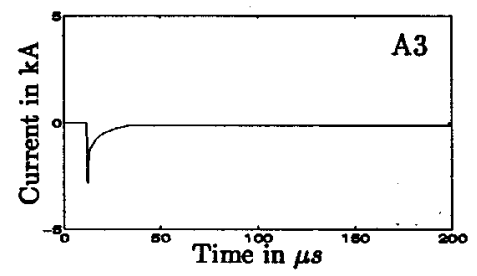

(c)

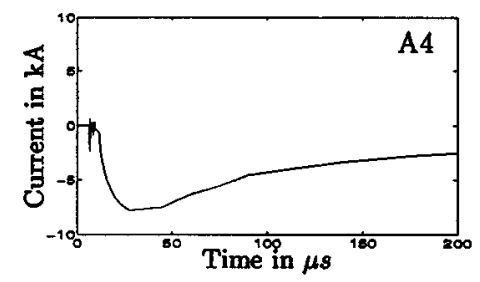

(d)

Fig. 12. Current versus time waveforms for configuration 97-C (see Table I). (a) Injected lightning current $[\mathrm{A} 1+\mathrm{A} 2]$. (b) Current to ground at node $\mathrm{A}(41 \Omega)$ [A1]. (c) Current to ground at node B (76 $\Omega$ ) [A3]. (d) Current entering the test house's electrical circuit [A4]. charge is determined by the integration of current and, therefore, is independent on current waveshape.

It might appear that the narrow current pulses observed in the ground rods at the test house could be also explained if one assumed these rods to be purely resistive and to be separated from the remote ground rods by a large inductance. Indeed, when a lightning current is injected into a resistive ground rod connected to another ground rod via a large inductance, the higher frequency components characteristic of the initial rising portion of the current waveform are blocked by the large inductance from flowing toward the "remote" rod and, as a result, are forced to flow into the "local" rod. For the later portion of the lightning current waveform that is characterized by relatively low frequency components, the inductance presents a smaller impedance, and, therefore, the lower-frequency components are allowed to flow toward the "remote" rod. In this view, at later times the division of current between the ground rod at the current injection point and the remainder of the system is determined by grounding resistances in the system (e.g., Birkl et al., 1996 [7]). This inference from the R-L circuit representation of the system is inconsistent with the experimental data presented in this paper, as we discuss next. After some tens of microseconds or less (after some microseconds for configuration 97-A), currents in the ground rods at the test house are essentially zero, while appreciable current, of the order of kiloamperes, flows into the system at $200 \mu$ s and beyond. For configurations 97-B and $97-\mathrm{C}$, if the ground rods were purely resistive, they would be conducting a larger current than the current flowing toward IS1 and IS4 at later times, because the total resistance of the two ground rods at the test house ( $41 \Omega$ in parallel with $76 \Omega$ ) is smaller than the total resistance of ground rods at IS1 and IS4 (69 $\Omega$ in parallel with $124 \Omega$ ). Further, the results of our EMTP modeling, with all inductances in the test system being taken into account, show that the narrow current pulses observed in the two ground rods at the test house cannot be reproduced if these rods are represented by resistors. 
TABLE II

Selected Peak Currents (Absolute Values) Measured at the Test House for the Three Different Configurations VERSUS THE IEC HyPOTHETICAL CURRENT Distribution SHOWN IN FIg. 1(a)

\begin{tabular}{|c|c|c|c|c|c|c|c|c|c|c|c|c|c|c|}
\hline \multirow[t]{2}{*}{ Configuration } & \multicolumn{2}{|c|}{$\begin{array}{l}\text { Injected } \\
\text { Light- } \\
\text { ning } \\
\text { Current }\end{array}$} & \multicolumn{2}{|c|}{$\begin{array}{l}\text { Current } \\
\text { to } \\
\text { Ground, } \\
\text { Node A }\end{array}$} & \multicolumn{2}{|c|}{$\begin{array}{l}\text { Current } \\
\text { from } \\
\text { Node } \\
\text { A to } \\
\text { Node } \\
\text { B }\end{array}$} & \multicolumn{2}{|c|}{$\begin{array}{l}\text { Current } \\
\text { to } \\
\text { Ground, } \\
\text { Node B }\end{array}$} & \multicolumn{2}{|c|}{$\begin{array}{l}\text { Current } \\
\text { into } \\
\text { House }\end{array}$} & \multicolumn{2}{|l|}{$\begin{array}{l}\text { Current } \\
\text { Through } \\
\text { SPDs }\end{array}$} & \multicolumn{2}{|c|}{$\begin{array}{l}\text { Current } \\
\text { to } \\
\text { Trans- } \\
\text { former } \\
\text { Sec- } \\
\text { ondary } \\
\text { Neu- } \\
\text { tral }\end{array}$} \\
\hline & $\mathrm{kA}$ & $\%$ & $\mathrm{kA}$ & $\%$ & $\mathrm{kA}$ & $\%$ & $\mathrm{kA}$ & $\%$ & $\mathrm{kA}$ & $\%$ & $\mathrm{kA}$ & $\%$ & $\mathrm{kA}$ & $\%$ \\
\hline$\overline{97-A}$ & 14 & 100 & 2.8 & 20 & 14 & 100 & 1.8 & 13 & 14 & 100 & $3.2 / 4.7^{\mathrm{a}}$ & $23 / 34^{\mathrm{a}}$ & $4.6^{\mathrm{b}}$ & $33^{\mathrm{b}}$ \\
\hline $97-\mathrm{B}$ & 14 & 100 & 6 & 43 & 13 & 93 & 4 & 29 & $13^{\mathrm{c}}$ & 93 & $>6.1$ & $>44$ & 7 & 50 \\
\hline $97-\mathrm{C}$ & 9.8 & 100 & 5.4 & 55 & 7.9 & 81 & 2.9 & 30 & 7.9 & 81 & - & - & $2.7^{\mathrm{b}}$ & $28^{\mathrm{b}}$ \\
\hline $\begin{array}{l}\text { IEC } \\
\text { (J.L. Koepfinger) }\end{array}$ & $100^{\mathrm{d}}$ & 100 & 50 & 50 & 50 & 50 & 25 & 25 & $\begin{array}{c}25 \\
(50)^{\mathrm{e}}\end{array}$ & $\begin{array}{c}25 \\
(50)^{\mathrm{e}}\end{array}$ & 12.5 & 12.5 & 12.5 & $\overline{12.5}$ \\
\hline
\end{tabular}

a Two peaks of bipolar waveform.

b Rough estimates obtained using measured peak currents at the transformer and Kirchhoff's current law.

c Rough estimates obtained using measured peak currents at the test house and Kirchhoff's current law.

$\mathrm{d}$ The maximum value of current corresponding to the IEC protection levels III/IV (IEC 61024-1[4]) typically assign $\epsilon$ to ordinary residential buildings.

e Values in the parentheses correspond to the current distribution illustraded in Figure 1b.

TABLE III

Selected Peak Currents (in Percent of Injected PeaK Current) Measured at the Test House for the Three DifFerent Configurations Versus

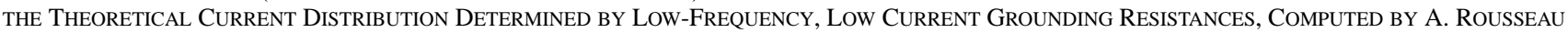

\begin{tabular}{l|l|l|l|l|l}
\hline \multirow{2}{*}{ Configuration } & $\begin{array}{l}\text { Current } \\
\text { Distribu- } \\
\text { tion }\end{array}$ & $\begin{array}{l}\text { Injected } \\
\text { Lightning } \\
\text { Current, \% }\end{array}$ & $\begin{array}{l}\text { Current } \\
\text { to } \\
\text { Ground } \\
\text { Node A, } \\
\%\end{array}$ & $\begin{array}{l}\text { Current } \\
\text { to } \\
\text { Ground, } \\
\text { Node B, } \\
\%\end{array}$ & $\begin{array}{l}\text { Current } \\
\text { into House, } \\
\%\end{array}$ \\
\hline \multirow{3}{*}{$97-$ A } & Measured & 100 & 20 & 13 & 100 \\
\cline { 2 - 7 } & Computed & 100 & 4 & 12 & 84 \\
\hline \multirow{3}{*}{$97-$ B } & Measured & 100 & 43 & 29 & 93 \\
\cline { 2 - 7 } & Computed & 100 & 40 & 22 & 38 \\
\hline \multirow{3}{*}{$97-$ C } & Measured & 100 & 55 & 30 & 81 \\
\cline { 2 - 7 } & Computed & 100 & 40 & 22 & 38 \\
\hline
\end{tabular}

Measured peak currents do not add to $100 \%$ due to considerable differences in current waveshapes.

We now discuss the suggested capacitive behavior of ground rods. Grcev [8] theoretically showed that a capacitive behavior should be expected, above a so-called characteristic frequency, for relatively short ground rods in relatively-low-conductivity soils. For frequencies below the characteristic frequency, grounding impedance is independent of frequency, that is, is resistive, while for frequencies above the characteristic frequency the grounding impedance either increases (inductive behavior) or decreases (capacitive behavior) with increasing frequency. The characteristic frequency decreases with increasing soil conductivity and with increasing grounding electrode length. For soil with an electrical conductivity of $10^{-3} \mathrm{~S} / \mathrm{m}$ (a factor of 4 higher than the measured soil conductivity at Camp Blanding) and a relative permittivity of 10 , the characteristic frequency decreases from about $500 \mathrm{kHz}$ to about $5 \mathrm{kHz}$ as the length of the grounding electrode increases from 2 to $128 \mathrm{~m}$, with the electrode's behavior changing from capacitive to inductive at a length of $16 \mathrm{~m}$ [8]. However, the capacitive behavior described above is expected only for the initial rising portion of the injected current waveforms [Figs. 4(a), 8(a), and 12(a)], while the observed essentially zero current in ground rods at the test house at later times suggests a capacitive behavior of these rods also during the tail portion of the injected current. It appears that the impedance to ground at the test house at later times is much higher than the impedance seen looking toward the rest of the system, regardless of the fact that the dc grounding resistances of the two rods at the house varied from more than a thousand ohms to tens of ohms. The results of our EMTP modeling show that the narrow current pulses observed in the two ground rods at the test house can be reproduced if the capacitances of these rods are set at some tens of nanofarads, although some current continues to flow through the rods at 
later times. These values of capacitances are about a factor of 200 larger than those computed using the standard formula for capacitance of a vertical ground rod (e.g., Mata et al. (2000) [9]), as if there were a thin layer of dielectric (of the order of $0.1 \mathrm{~mm}$ for dry sand or $0.02 \mathrm{~mm}$ for air) between the metallic rod and the surrounding better conducting (wet sand) soil.

\section{RECOMMENDATIONS}

The experimental results presented in this paper are for sandy soil of relatively low conductivity. It is important to conduct similar experiments for other types of soil. It is possible that for higher-conductivity soils the apparent capacitive behavior of the ground rods will be less pronounced. It is not clear why such capacitive behavior is not seen in currents flowing to ground at IS1 and IS4. Further, it would be interesting to test the effect that chemicals which are sometimes added to the soil around the grounding electrode to make the soil more conductive would have on the behavior of the grounding electrodes under lightning surge conditions. Finally, other grounding electrode geometrics (including ring electrode) should be tested.

\section{SUMMARY}

The grounding system of a test house was subjected to triggered-lightning dicharges for three different configurations, with the house's electrical circuit being connected to the secondary of a transformer in IS1, about $50 \mathrm{~m}$ distant. The primary of the transformer was connected to the underground cable which was open-circuited at IS4. The cable's neutral was grounded at IS1 and IS4. The division of lightning current injected into the grounding system of the test house among the various paths in the overall system was analyzed. The ground rods at the test house appeared to filter out the higher frequency components of the lightning current, allowing the lower frequency components to enter the house's electrical circuit. In other words, the ground rods exhibited a capacitive rather than the often expected and usually modeled resistive behavior. This effect was observed for dc resistances of the ground rods (in typical Florida sandy soil) ranging from more than a thousand ohms to some tens of ohms. The peak value of the current entering the test house's electrical circuit was found to be over $80 \%$ of the injected lightning current peak, in contrast with the $25 \%$ or $50 \%$ assumed in two IEC-suggested scenarios. Also, the percentages of current flowing a) to the transformer secondary neutral and $b$ ) through the SPDs were observed to be approximately a factor of two to four greater than those assumed in the IEC hypothetical scenario illustrated in Fig. 1(a). Since the current waveshapes may differ considerably throughout the system, charge transfer is apparently a better quantity than the peak current for studying the division of lightning current among the various paths in the system.

\section{ACKNOWLEDGMENT}

The authors would like to thank the Electric Power Research Insitute (Project Manager R. Bernstein), Duquesne Light Co. (Project Manager J. L. Koepfinger), and the National Science Foundation. J. L. Koepfinger participated in designing the three tested configurations and provided information presented in Fig. 1(a). A. Rousseau provided computed current distributions presented in Table III. R. Bernstein, J. Koepfinger, F. Martzloff, J. Osterhout, and H. Steinhoff made a number of useful comments on the results of this study. The authors would like to thank P. Hasse, L. Grcev, A. Rousseau, V. Shostak, W. Zischank, and three anonymous reviewers for their careful reading of the paper and for comments and suggestions that helped to improve the manuscript.

\section{REFERENCES}

[1] Protection Against Lightning Electromagnetic Impulse, Part 1: General Principles, IEC 61312-1, 1995.

[2] V. A. Rakov, M. A. Uman, K. J. Rambo, M. I. Fernandez, R. J. Fisher, G. H. Schnetzer, R. Tottappillil, A. Eybert-Berard, J. P. Berlandis, P. Lalande, A. Bonamy, P. Laroche, and A. Bondiou-Clergerie, "New insights into lightning processes gained from triggered-lightning experiments in Florida and Alabama," J. Geophys. Res., vol. 103, pp. 14 117-14 130, 1998.

[3] M. I. Fernandez, C. T. Mata, V. A. Rakov, M. A. Uman, K. J. Rambo, M. V. Stapleton, and M. Bejleri, "Improved lightning arrester protection results, final results," Electric Power Res. Inst. (EPRI), Tech. Rep. TR-109 670-R1, Dec. 1998.

[4] Protection of Structures Against Lightning, Part 1: General Principles, IEC 61 024-1, 1990.

[5] A. Rakotomalala, P. Auriol, and A. Rousseau, "Lightning distribution through earthing system," Proc. IEEE Int. Symp. EMC, pp. 419-423, 1994.

[6] M. Bejleri, V. A. Rakov, M. A. Uman, K. J. Rambo, C. T. Mata, and M. I. Fernandez, "Triggering lightning testing of an airport runway lighting system," in Proc. 25th Int. Conf. Lightning Protection, Rhodes, Greece, 2000, pp. 825-830.

[7] J. Birkl, P. Hasse, and P. Zahlmann, "Investigation of the interaction of lightning currents with low-voltage installations and their related lightning threat parameters," in Proc. 23rd Int. Conf. Lightning Protection, Florence, Italy, 1996, pp. 622-627.

[8] L. Grcev, "Improved earthing system design practices for reduction of transient voltages," in Proc. CIGRE, Sess. paper 36-302, 1998.

[9] C. T. Mata, M. I. Fernandez, V. A. Rakov, and M. A. Uman, "EMTP modeling of a triggered-lightning strike to the phase conductor of an overhead distribution line," IEEE Trans. Power Delivery, vol. 15, pp. $1175-1181,2000$.

Vladimir A. Rakov received the M.S. and Ph.D. degrees from Tomsk Polytechnical University (Tomsk Polytechnic), Tomsk, Russia, in 1977 and 1983, respectively.

He is a Professor of the Department of Electrical and Computer Engineering, University of Florida (UF), Gainesville. He is the author or co-author of over 30 patents and over 200 papers and technical reports on various aspects of lightning, with 75 papers being published in reviewed journals. From 1977 to 1979, he worked as an Assistant Professor of Electrical Engineering at Tomsk Polytechnic. In 1978, he became involved in lightning research at the High Voltage Research Institute, a division of Tomsk Polytechnic, where from 1984 to 1994 he held the position of Director of the Lightning Research Laboratory. In 1985, he received the rank of Senior Scientist in High Voltage Engineering. In 1991, he joined the Faculty of the Department of Electrical and Computer Engineering at UF. In 1998, he was Guest Professor at the Technical University of Vienna, Austria, and in 2001 at the Swiss Federal Institute of Technology in Lausanne.

Dr. Rakov was named an Inventor of the USSR (1986) and received a Silver Medal from the (USSR) National Exhibition of Technological Achievements (1987). He is a member of the American Geophysical Union (AGU), the American Meteorological Society (AMS), the Society of Automotive Engineers (SAE). He is also a member of the CIGRE Working Group 33.01 "Lightning," the IEEE Working Group on the Lightning Performance of Distribution Lines, the International Commission on Atmospheric Electricity, the Steering Committee for the International Symposium on Lightning Protection (SIPDA), the AMS Science and Technology Committee on Atmospheric Electricity, the Scientific Committee of the International Conference on Lightning Protection (ICLP), and the UL Standards Technical Panel for Lightning Protection Components. He is Chairman of the Technical Committee on Lightning of the Biennial International Zurich Symposium on Electromagnetic Compatibility and of the AGU Committee on Atmospheric and Space Electricity (CASE). 
Martin A. Uman received the B.S., M.S., and Ph.D. degrees from Princeton University, Princeton, NJ.

He is Professor and Chair of the Department of Electrical and Computer Engineering, University of Florida (UF), Gainesville. He has written three books on the subject of lightning (two now in revised second editions), as well as a book on plasma physics, ten book chapters and encyclopedia articles on lightning, and has published over 150 papers in reviewed journals and over 160 articles and reports in other publications. He holds five patents, four in the area of lightning detection. He was an Associate Professor of electrical engineering at the University of Arizona, Tucson, from 1961 to 1964 . He joined the UF Faculty in 1971 after working for seven years as a Fellow Physicist at Westinghouse Research Labs, Pittsburgh, PA. He cofounded and served as President of Lightning Location and Protection, Inc. (LLP) from 1975 to 1985.

Dr. Uman was the recipient of the 2001 American Geophysical Union John Adam Fleming Medal for original research and technical leadership in geomagnetism, atmospheric electricity, space science, aeronomy, and related sciences for "outstanding contribution to the description and understanding of electricity and magnetism of the Earth and its atmosphere." He was the recipient of the 1996 IEEE Heinrich Hertz Medal for "outstanding contributions to lightning detection and protection." He was named the 1990 Florida Scientist of the Year by the Florida Academy of Sciences and honored as 1988 to 1989 University of Florida Teacher-Scholar of the Year: the highest UF faculty award. He is a Fellow of two professional organizations: the American Geophysical Union (AGU) and the American Meteorological Society (AMS). Other awards include NASA's 1992 and 1996 Group Achievement Awards to the Galileo Probe Spacecraft Team.

Mark I. Fernandez received the B.S. degree from Florida Institute of Technology (FIT), Melbourne, in 1995 and the M.S. degree from the University of Florida (UF), Gainesville, in 1997.

He was involved in magnetostatics and space plasma research as an undergraduate in the Department of Physics and Space Science at FIT. From 1995 to 1997 , he held a graduate research assistantship in the UF lightning Research Laboratory. He is author or co-author of five publications in reviewed journals, 11 published abstracts or conference proceedings, and four technical reports.

Mr. Fernandez is a member of the American Geophysical Union.

Carlos T. Mata received the B.S. degree from the Universidad Simón Bolívar (USB), Baruta, Venezuela, in 1993 and the M.S. and Ph.D. degrees from the University of Florida (UF), Gainesville, in 1997 and 2000, respectively.

$\mathrm{He}$ is involved in the area of computer modeling of different lightning processes and responses of power distribution systems to direct and nearby lightning strikes. He currently works at the Kennedy Space Center doing embedded system and advanced data acquisition systems design in support to the Space Shuttle program. He is author or co-author of six journal publications and seven technical reports.

Dr. Mata is a member of the American Geophysical Union (AGU) and the Power Engineering Society (PES). In 1998, he was awarded the GAANN fellowship and in 2001 the IEEE Power Engineering Society SPDC Prize Paper Award.
Keith J. Rambo received the B.S.E.E. degree from the University of Florida (UF), Gainseville, in 1978.

As an undergraduate he worked in the UF Lightning Research Laboratory. From 1979 to 1983 he was Senior Process Development Engineer of Intel Corporation in Santa Clara, CA. From 1983 through 1986 he was a Product Line Manager for Xicor, responsible for all aspects of wafer fabrication. In 1986, he joined the UF Department of Electrical and Computer Engineering where since 1989 he has been Director of Technical Support Services. Since 1994, he has been heavily involved in triggered-lightning experiments at Camp Blanding, FL. He has 10 technical publications.

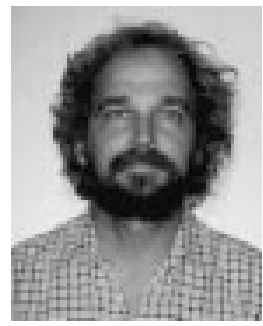

Michael V. Stapleton attended Broward Community College, Fort Lauderdale, FL, and Florida Atlantic University, Boca Raton.

He has worked in the research and development lab for Medcor Corp., a pacemaker company, for Harris Computer Systems Division, and for Select Engineered Systems developing hardware and software for security systems. In 1996, he joined the Department of Electrical and Computer Engineering, University of Florida, Gainesville. Since 1996, he has been heavily involved in triggered-lightning experiments at Camp Blanding, FL.

Rafael R. Sutil received the B.S. degree from the Universidad Simón Bolívar (USB), Baruta, Venezuela in 1993 and the M.S. degree from the University of Florida, Gainesville, in 2001.

From 1999 to 2001, he held a Graduate Research Assistantship in the UF Lightning Research Laboratory. He is involved in the area of lightning protection and computer modeling. He co-authored two technical papers. 